\title{
XIAP as a Radioresistance Factor and Prognostic Marker for Radiotherapy in Human Rectal Adenocarcinoma
}

\author{
Driffa Moussata, ${ }^{* \dagger}$ Souheila Amara, ${ }^{\dagger+}$ \\ Bénazir Siddeek, ${ }^{\dagger \ddagger}$ Myriam Decaussin, ${ }^{\dagger \S}$ \\ Stephanie Hehlgans, "Rachel Paul-Bellon, ${ }^{\text {†‡ }}$ \\ Françoise Mornex," Jean-Pierre Gerard," \\ Pascale Romestaing," Franz Rödel," \\ Bernard Flourie, ${ }^{*}$ Mohamed Benahmed, ${ }^{\dagger * * *}$ and \\ Claire Mauduit ${ }^{\dagger+\dagger}$

\begin{abstract}
From the Services de Gastroentérologie* et Radiothérapie, the Laboratoire d'Anatomie et de Cytologie Pathologiques, ${ }^{\S}$

Hospices Civils de Lyon, Hôpital Lyon Sud, Pierre-Bénite, France; INSERM, ${ }^{\dagger}$ Centre Méditerranéen de Médecine Moléculaire, Equipe Environnement Reproduction et Cancers Hormono-Dépendants: Mécanismes Épigénomiques, Nice, France; the Université de NiceSophia Antipolis, ${ }^{\ddagger}$ Faculté de Médecine, Institut Signalisation et Pathologie, Nice, France; the Department of Radiation Therapy and Oncology," University of Frankfurt, Frankfurt, Germany; the Centre Hospitalier Universitaire de Nice,** Hôpital Archet II, Pôle de Obstétrique Reproduction Gynécologie Study and Conservation of Sperm Center, Nice, France; and the Unit of Formation and Research, ${ }^{+\dagger}$ Université Lyon 1, Médecine Lyon
\end{abstract} \\ Sud, Oullins, France
}

A differential responsiveness of patients to ionizing radiation is observed after preoperative radiotherapy for rectal adenocarcinoma that might be related, in part, to an apoptosis defect. To establish if proteins of the apoptotic cascades [pro-apoptotic: active caspase 3,8 , and 9 and DIABLO (direct inhibitor of apoptosisbinding protein with low pI); anti-apoptotic: XIAP (X-linked inhibitor of apoptosis)] are involved, we analyzed their profile in radioresistant (SW480) and radiosensitive ( $\mathrm{SW} 48$ ) human colorectal cell lines. We demonstrated that, after irradiation, the $S W 48$ cells increased the expression of the pro-apoptotic proteins, whereas the $S W 480$ cells increased the expression of the anti-apoptotic protein XIAP. Moreover, XIAP knockdown in SW480 cells enhanced the basal and radiation-induced apoptotic index; the propensity of the $\mathrm{SW} 480$ cells to undergo apoptosis after radiation was higher compared with $\mathrm{SW} 48$ cells. In a translational study of 38 patients with rectal carci- noma, we analyzed the apoptotic profile for tumor and noncancerous tissue for each biopsy specimen using IHC. According to their response to preoperative radiotherapy, patients were classified into two groups: responsive and nonresponsive. Although no difference in expression of caspase 3, 8, or 9 was observed in the tumor/normal tissue ratio between responsive and nonresponsive patients, the ratio decreased for DIABLO and increased for XIAP. In conclusion, inhibition of XIAP rescues cellular radiosensitivity and both DIABLO and XIAP might be potential predictive markers of radiation responsiveness in rectal adenocarcinoma. (Am J Patbol 2012, 181:1271 -1278; http://dx.doi.org/10.1016/j.ajpath.2012.06.029)

Preoperative administration of radiotherapy or radiochemotherapy in rectal cancer results in a down-staging effect that enhances the rate of curative surgery in lesions that are unresectable at presentation or may enable sphincter preservation in low-lying tumors. ${ }^{1-4}$ A complete response to preoperative radiotherapy is observed in $4 \%$ to $30 \%$ of patients, and down staging occurs in $30 \%$ to $60 \%$ of the cases. ${ }^{3,5-7}$ Although preoperative radiation clearly improved local recurrence compared with surgery alone, the magnitude of benefit was heterogeneous across the trials. ${ }^{8}$ A possible explanation, in addition to tumor size and differentiation status, is the gene profile

Supported by the French Institute for Health and Medical Research (INSERM U407), La Ligue contre le Cancer (comité départemental de l'Ain et du Rhône), Association pour la Recherche sur le Cancer (contract 9678 and fellowship A02/4, 2003, to D.M.), Electricité de France (RB 98-37), l'Académie Nationale de Médecine, and the Ministère de la Recherche et de la Technologie (Radiobiologie, DS5)

Accepted for publication June 11, 2012

D.M. and S.A. contributed equally to this work.

Supplemental material for this article can be found at http://ajp. amjpathol.org or at http://dx.doi.org/10.1016/j.ajpath.2012.06.029.

Address reprint requests to Claire Mauduit, Ph.D., Inserm Unité 1065 Équipe 5, Bâtiment Universitaire Archimed, Centre Hospitalier l'Archet 2 151 Route St Antoine Ginestière, BP 2 3194, 06204 Nice CEDEX 3, France. E-mail: mauduit@univ-lyon1.fr. 
expression in individual lesions. Although it is possible to identify patients with a radioresponsive tumor at the time of diagnosis, a selective and individualized policy of preoperative radiotherapy as well as less radical surgery might be pursued.

Among the molecular mechanisms potentially involved in the differential response of rectal carcinoma to radiation, an association has been observed between the apoptotic rate and the radiosensitivity of the tumor. ${ }^{9-11}$ Moreover, either by genome-wide ${ }^{12}$ or candidate gene approaches, ${ }^{13-17}$ several apoptotic proteins [BCL2, BAX, pro-caspase (CASP), and Survivin] or apoptosis-related genes (TP53 and p21) have been described as being involved in the response of rectal carcinoma to radiation, suggesting that apoptotic cell death may play an important role in determining the response to radiotherapy. However, the role of caspases (through their active form) and the involvement of a different type of proteins of the executioner step of apoptosis remain to be elucidated. This step is under the control of cysteine proteases, named effectors CASP3, CASP6, and CASP7, that are activated by initiator caspases, such as active CASP8 and CASP10, for the death receptor pathway, and active CASP9 for the mitochondrial pathway. ${ }^{18,19}$ Effector caspase activity, in turn, is controlled by members of the inhibitor of apoptosis protein family (IAP). ${ }^{20}$ Baculoviral IAP repeat-containing (BIRC) 4/X-linked inhibitor of apoptosis (XIAP) is the most thoroughly characterized IAP. IAPs bind to and inhibit caspase activation and/or activity. ${ }^{21}$ Furthermore, apoptosis-promoting proteins located inside the mitochondria, such as direct inhibitor of apoptosis-binding protein with low pl (DIABLO), are antagonized by the caspase-inhibiting effects of XIAP. ${ }^{22}$ Overall, the relative levels of the three types of proteins (effector caspases, IAPs, and inhibitors of IAPs) will preside over the apoptotic fate of the cells.

In our study, we aimed to establish the involvement of active CASPs 3, 8, and 9, DIABLO, and XIAP in the radioresistance process by comparing their profile in radioresistant (SW480) and radiosensitive (SW48) human colon cell lines and to assess the effects of knockdown of XIAP on cell line response to ionizing radiation. To confirm the in vitro data at the clinical level, we analyzed the expression of these proteins in rectal carcinoma tissues from patients characterized as responsive or nonresponsive to preoperative radiotherapy by a semiquantitative immunohistochemical $(\mathrm{IHC})$ approach.

\section{Materials and Methods}

\section{Cell Culture and Irradiation Procedure}

Human colorectal adenocarcinoma cell lines SW48 and SW480, with diverse and characterized ${ }^{23}$ intrinsic radiosensitivities, were obtained from ATCC (LGC-Promochem, Wiesbaden, Germany). The cells were cultured in Dulbecco's modified Eagle's medium supplemented with $10 \%$ fetal calf serum, $1 \%$ sodium pyruvate, and 2 $\mathrm{mmol} / \mathrm{L}$ glutamine and seeded at a density of 15,000 cells $/ \mathrm{cm}^{2}$. The cells were transfected (20 to $50 \mathrm{nmol} / \mathrm{L}$ ) with a small-interfering RNA (siRNA; MWG Biotech AG, Washington, DC) raised against Xiap (5'-UGCAAGAGCUGGAUUUUAUGCTT-3') or a nonspecific scramble siRNA (5'-UGGGACUAAGUUAGUAUCGUCTT-3') or incubated with the Interferin Transfection reagent (Polyplus-Transfection SA, Illkirch, France) alone for 48 hours. Next, fresh culture medium was added to cells before being irradiated with a single dose of 2 or 5 Gy, with a dose rate of $20.44 \mathrm{mGy} / \mathrm{s}$ (Clinac 2100/CD; VARIAN Medical Systems, Palo Alto, CA).

\section{Colony-Forming Assay}

The clonogenic colony-forming assay was performed as previously described. ${ }^{24}$ Briefly, SW48 or SW480 cells were transfected with either XIAP-specific siRNA or nonspecific scrambled siRNA or incubated with the transfection reagent, as described in "Cell Culture and Irradiation Procedure". For colony-forming assays, cells were plated as single cells into six-well plates (BD, Heidelberg, Germany) in triplicate, 24 hours after transfection. After an additional 24 -hour incubation at $37^{\circ} \mathrm{C}$ and $5 \% \mathrm{CO}_{2}$, cells were irradiated at room temperature with single doses of $\mathrm{X}$-ray (0, 2, or 6 Gy). Colonies were stained with methylene blue solution for 30 minutes, and colonies ( $>50$ cells) were counted subsequently at 19 (SW48) or 13 (SW480) days after plating.

Calculation of surviving fractions was performed according to the following equation:

Surviving Fraction $=$ Colonies Counted/Cells Seeded $\times$ (Plating Efficiency/100), considering the individual plating efficiency.

Survival variables $\alpha$ and $\beta$ were fitted according to the following linear quadratic equation: Surviving Fraction = $\exp \left[(-\alpha \times D)-\left(\beta \times D^{2}\right)\right]$, with $D=$ dose, using EXCEL software (Microsoft, Unterschleißheim, Germany).

All experiments were repeated three times. Radiationinduced cytotoxicity enhancement factors at $50 \%$ and $10 \%$ survival were calculated by transforming the previously mentioned equation using $\alpha$ and $\beta$ values of the individual survival curves.

\section{Apoptotic Assays}

The apoptotic rate in SW48 and SW480 cell lines was assessed using flow cytometric detection of annexin V-fluorescein isothiocyanate (Miltenyi Biotec $\mathrm{GmbH}$, Gladbach, Germany), according to the instructions of the manufacturer. CASP3 activity was measured in SW48 and SW480 cell lines using a colorimetric assay kit (Alexis Biochemicals, Paris, France), according to the manufacturer's instructions.

\section{Western Blot Analysis}

SW48 and SW480 cells were homogenized in $200 \mu \mathrm{L}$ of ice-cold hypotonic buffer $(25 \mathrm{mmol} / \mathrm{L}$ Tris- $\mathrm{HCl}, \mathrm{pH} 7.4$, containing protease inhibitor cocktail). Protein concentration was determined using the bicinchoninic acid assay. ${ }^{25}$ Proteins (5 to $10 \mu \mathrm{g}$ ) were separated on $10 \%$ polyacrylamide gels and transferred to nitrocellulose 
membranes. ${ }^{25}$ The membranes were incubated overnight at $4^{\circ} \mathrm{C}$ with the primary antibodies (see IHC Data), and equal protein loading was confirmed by reprobing the blot with a rabbit IgG anti-actin antibody (1:600; Sigma-Aldrich, L'Isle D'Abeau, France). The antigen-antibody complexes were visualized by using a chemiluminescent kit (Covalight; Covalab, Lyon, France). Biomax MR films (Sigma) were scanned, and the estimated intensity of the bands was quantified using the Optiquant software package (Packard, Meriden, CT).

\section{Preoperative Radiochemotherapy Protocol}

A cohort of 38 patients with locally advanced rectal carcinoma received preoperative radiochemotherapy before surgery using a total dose of 45 Gy in daily fractions of 1.8 Gy on 5 consecutive days per week. During the first and fifth weeks of radiotherapy, 5-fluorouracil was delivered at a dose of $350 \mathrm{mg} / \mathrm{m}^{2}$ per day; and folinic acid was delivered at a dose of $20 \mathrm{mg} / \mathrm{m}^{2}$. The TNM was assessed by ultrasonography before radiotherapy, and the ypTNM staging was determined based on the surgical specimens. (ypTNM describes the anatomic extent of disease after surgery.) Two groups of patients (patients who were responsive and nonresponsive to radiotherapy) were determined by comparing the ultrasonographic TNM with the ypTNM. After treatment, the tumor stage grouping (ypTNM) in the responsive group was changed in all patients [19 (100\%) of 19] because no more tumoral tissue was observed (complete regression). In the nonresponsive group, of 19 patients, the ypT stage was decreased for 7 (36.8\%), unchanged for 10 (52.6\%), and increased for the remaining $2(10.5 \%)$. Moreover, in the 19 patients, the ypN stage was decreased in $9(47.4 \%)$, unchanged in 6 (31.6\%), and increased in 4 (21.1\%). The ethics committee of the medical faculty and the state medical board agreed to these investigations and an informed consent was obtained from all patients.

\section{IHC Data}

Tissues were immediately fixed for 24 hours in Bouin's fluid and handled as previously described. ${ }^{25}$ The Envi$\operatorname{sion}^{+}$kit (Dako, Trappes, France) was used with antiTP53 (1:800; BD Biosciences, Le Pont de Claix, France), anti-DIABLO (1:2000; Santa Cruz Biotechnology, Santa Cruz, CA), and anti-cleaved CASP8 (1:150; Ozyme, Saint Quentin Yvelines, France) antibodies. The CSAll (BiotinFree Tyramide Signal Amplication) system (Dako) was used with anti-cleaved CASP9 antibodies (1:400; Clinisciences, Montrouge, France), and an LSAB kit (Dako) was used with anti-XIAP (1:80; BD Biosciences) and anticleaved CASP3 (1:80; Ozyme) antibodies. Two independent pathologists (M.D. and D.M.), blinded to the clinicopathologic variables, evaluated the immunostaining. The immunostaining score was evaluated based on the whole slide. The results were recorded by assessing the percentage of positive cells and the intensity of the staining (1, mild; 2 , moderate; 3 , intense) on the tumoral and the nontumoral areas for each slide, as previously described. ${ }^{26}$ Immuno- staining scores were calculated by multiplying the percentage of labeled cells by the intensity of staining.

\section{Data Analysis}

In vitro experiments were realized in quadruplicate and were performed at least three times in independent experiments. A one-way analysis of variance for dependent groups was performed to determine whether there were differences between all groups, followed by a Bonferroni post hoc test, if $P<0.05$ in the analysis of variance, to determine the significance $(P<0.05)$ of differences between pairs of groups. A Mann-Whitney test was used to compare the expression in tumor and noncancerous tissue and to compare the ratio for tumoral/nontumoral tissue between responsive and nonresponsive groups of patients. $P<0.05$ was considered significant. The statistical tests were performed using StatView software, version 5.0 (SAS Institute Inc., Cary, NC).

\section{Results}

\section{Effects of lonizing Radiation on SW480 and SW48 Cell Survival and Apoptotic Profile}

The radiation response characteristics of both cell lines were investigated using apoptotic cell death evaluation (see Supplemental Figure S1 at http://ajp.amjpathol.org). lonizing radiation induced a significant increase in the number of apoptotic SW48 cells at 2 Gy (4.6-fold, $P<$ $0.002)$ and 5 Gy $(6.8$-fold, $P<0.001)$. Although irradiation induced a significant increase of apoptotic SW480 cells at 2 Gy $(1.7$-fold, $P<0.006)$ and 5 Gy $(2.0$-fold, $P<$ 0.001 ), such an increase was two to three times less potent than in SW48 cells. Similar results were obtained with the kinetic study, confirming that the SW48 cell line was more sensitive to ionizing radiation than SW480 cells. To further analyze the diverse intrinsic radiation responses of these cell lines, we evaluated their apoptotic profile. In the SW48 cell line, irradiation induced a significant increase in active CASP8 protein levels at 2 Gy (1.5-fold, $P<0.0001$, Figure $1 \mathrm{~A}$ ) and 5 Gy (4.3-fold, $P<$ 0.0009 , Figure 1B). By contrast, irradiation of the SW480 cell line induced a significant decrease in active CASP8 protein levels at 2 Gy (5.3-fold, $P<0.0009$, Figure $1 \mathrm{~A}$ ) and 5 Gy (5.3-fold, $P<0.0001$, Figure 1B). Irradiation of SW48 cells induced a significant increase in CASP3 activity at 2 Gy (1.7-fold, $P<0.01$, Figure $1 \mathrm{C})$ or 5 Gy (2.1-fold, $P<0.0009$, Figure 1D), whereas irradiation of the SW480 cell line did not modify the CASP3 activity at 2 Gy (Figure 1C) but induced a significant increase at 5 Gy (1.4-fold, $P<0.03$, Figure 1D). For XIAP, irradiation of the SW48 cell line did not alter its protein expression with either 2 Gy (Figure 2A) or 5 Gy (Figure 2B). Irradiation of the SW480 cell line induced a significant increase in XIAP protein levels at 2 Gy (1.5-fold, $P<0.0003$, Figure 2A) and 5 Gy (1.5-fold, $P<0.0003$, Figure 2B). The expression of DIABLO was unchanged in SW48 cells irradiated at 2 Gy (Figure 2C) and 5 Gy (Figure 2D). Irradiation of the SW480 cell line induced a significant decrease in 

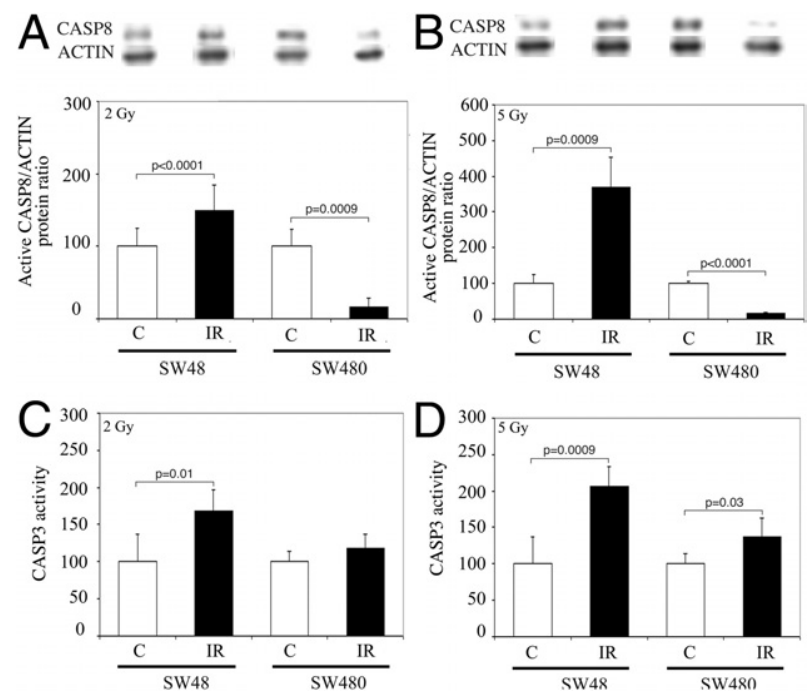

Figure 1. Expression of active CASP8 and CASP3 activity in SW48 and SW480 cells. Radiosensitive SW48 and radioresistant SW480 cells lines are mock irradiated (C) or irradiated (IR) with a dose of 2 Gy (A and C) or 5 Gy (B and D). Protein levels of active CASP8 (A and B) and CASP3 (C and $\mathbf{D})$ activity were determined 5 hours after harvesting. Antibody dilution was 1:200 for anti-cleaved CASP8. The results are expressed as the mean \pm SD from three independent experiments. Top panels, representative autoradiograms are shown.

DIABLO protein levels at 2 Gy $(4.9$-fold, $P<0.0001$, Figure $2 \mathrm{C}$ ) or 5 Gy (approximately 50-fold, $P<0004$, Figure 2D). These data suggested that the anti-apoptotic molecule XIAP and DIABLO (the XIAP inhibitor) are indicators for the differential radiation response of SW48 and SW480 cells.

\section{XIAP Knockdown Radiosensitized SW48 and SW480 Cells}

Under our experimental conditions, siRNA knockdown of XIAP decreased its protein levels by $98 \%$, whereas the transfectant reagent had no effect (Figure 3, A and C). Under nonirradiated or irradiated conditions, the apoptotic fraction for the transfectant reagent was similar to mock-treated cells (Figure 2E). XIAP knockdown induced a significant increase in the apoptotic rate of SW48 (1.6fold, $P<0.018$ ) and SW480 (threefold, $P<0.001$ ) cells compared with mock-treated cells (Figure 2E). Moreover, knockdown of XIAP, if combined with ionizing radiation, induced a fourfold $(P<0.002$, SW48) or a 5.3-fold $(P<$ 0.002 , SW480) increase in the apoptotic rate when compared with mock-treated cells (Figure 2E). Finally, the association of XIAP knockdown plus irradiation enhanced the apoptotic rate of SW480 cells, which reached a significantly higher level than the apoptotic rate of SW48 cells (1.3-fold, $P<0.008$, Figure $2 \mathrm{E}$ ).

To further establish a correlation between XIAP attenuation and radiation response, clonogenic survival assays were performed. Pre-incubation of SW48 cells (Figure $3 \mathrm{~A}$ ) and SW480 cells (Figure 3C) with XIAP siRNA slightly, but not significantly, increased basic clonogenic survival compared with the mock-treated controls. By contrast, XIAP siRNA transfection significantly radiosen- sitized SW48 (Figure 3B) and SW480 (Figure 3D) cells, resulting in a calculated radiation-induced cytotoxicity enhancement factor of $1.34\left(\mathrm{LD}_{50}\right)$ or $1.19\left(\mathrm{LD}_{10}\right)$ for SW48 and $1.33\left(\mathrm{LD}_{50}\right)$ or $1.11\left(\mathrm{LD}_{10}\right)$ for SW480 (Table 1).

\section{In Vivo Apoptotic Profile in Human Rectal Carcinoma Tissues}

We performed a semiquantitative $\mathrm{IHC}$ analysis for the different apoptotic molecules studied to evaluate if an alteration in the apoptotic profile might explain the radiation responsiveness of patients with rectal adenocarcinoma (see Supplemental Figure S2 at http://ajp.amjpathol. org). For each protein studied, we compared the following: its expression between the tumoral and circumjacent noncancerous tissue and the ratio for responsive/nonresponsive patients. The expression of active CASP8 (Figure 4A), active CASP9 (Figure 4B), and active CASP3 (Figure $4 C$ ) was significantly higher in tumors compared with noncancerous tissue in both responsive $(P<0.003$,

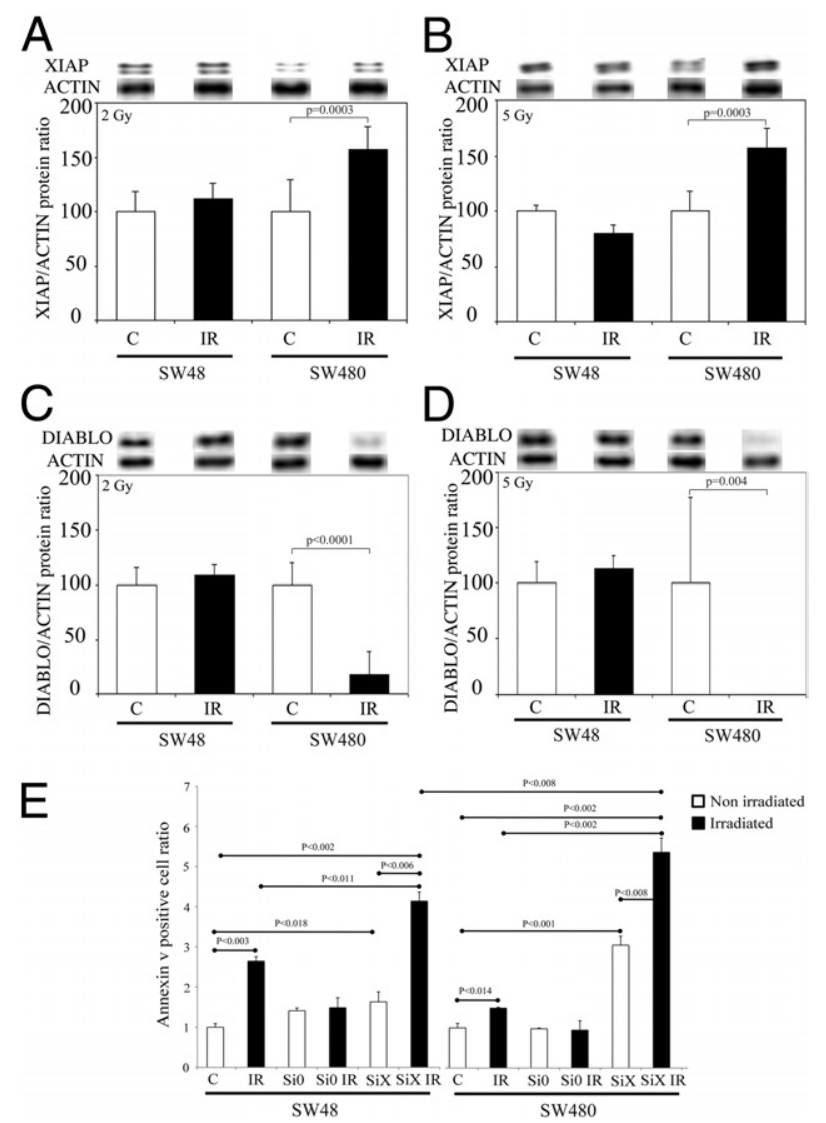

Figure 2. Expression of XIAP and DIABLO in SW48 and SW480 cells and increased apoptosis after XIAP knockdown. The radiosensitive SW48 and radioresistant SW480 cell lines were mock irradiated (C; white column) or irradiated (IR; black column) with a dose of 2 Gy (A and $\mathbf{C}$ ) or 5 Gy (B and D). XIAP (A and $\mathbf{B}$ ) and DIABLO $(\mathbf{C}$ and $\mathbf{D})$ protein levels were determined by using Western immunoblotting. The results are expressed as the mean \pm SD. Top panels, representative autoradiograms are shown. E: Radiosensitive SW48 and radioresistant SW480 cells were mock irradiated (C) or irradiated (IR) with a dose of $2 \mathrm{~Gy}$. The cells were incubated with the scrambled siRNA (Si0) or with an siRNA against XIAP (SiX) for 48 hours. At the end of the incubation time, the apoptotic rate was evaluated by annexin $\mathrm{V}$-propidium iodide flow cytometry. The histograms represent the ratio of annexin V-positive cells (mean $\pm \mathrm{SD})$. 

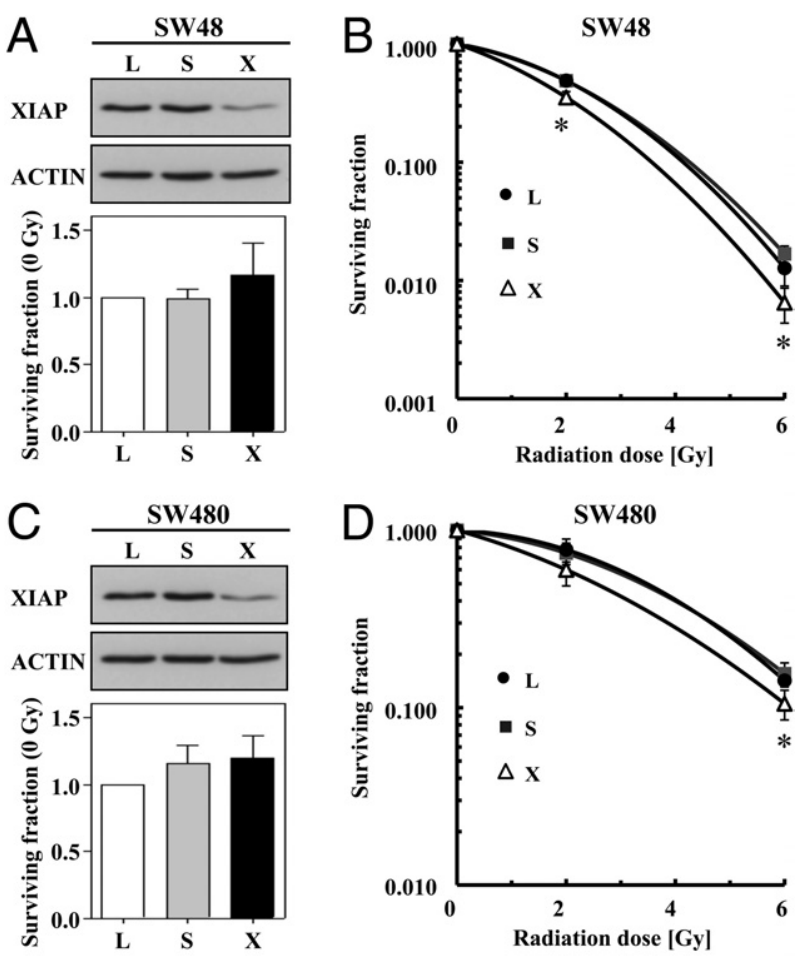

L: transfection reagent $\mathrm{S}$ : siRNA scramble $\mathrm{X}$ : siRNA XIAP

Figure 3. XIAP knockdown significantly radiosensitizes SW 48 and SW480 cells. Efficient knockdown of XIAP (SiX) compared with cells treated with the transfection reagent (L) or transfected with nonspecific scrambled siRNA (Si0) was confirmed by using Western blot analysis (A and $\mathbf{C}$ ). Actin served as a loading control. After transfection, cells were plated as single cells for a colony-forming assay, irradiated after 24 hours (X-ray, single dose, 0 to 6 Gy) and stained at 19 (SW48) or 13 (SW480) days after plating. Colonies were counted, and the plating efficiency was calculated. The histograms show the mean \pm SD surviving fraction of mock-irradiated $\mathrm{SiX}$ and $\mathrm{Si} 0$ cells relative to cells treated with the transfection reagent alone $(n=3)$. The surviving fraction of siRNA-transfected and irradiated (0, 2, and $6 \mathrm{~Gy})$, and cells were calculated for SW48 (B) and SW480 (D) cell lines. Results represent the mean \pm SD surviving fractions relative to mockirradiated cells $(n=3)$. A Student's $t$-test compared XIAP-depleted cells with siRNA-scrambled controls $(n=3) .{ }^{*} P<0.05$.

CASP8; $P<0.002$, CASP9; $P<0.001$, CASP3) and nonresponsive $(P<0.009$, CASP8; $P<0.002$, CASP9; $P<0.01$, CASP3) groups. By contrast, the ratio for tumor/ noncancerous tissue was unchanged for active CASP8 (Figure 4A), CASP9 (Figure 4B), and CASP3 (Figure 4C). The expression of XIAP (Figure 4D) was significantly higher in the tumor tissue compared with the noncan-
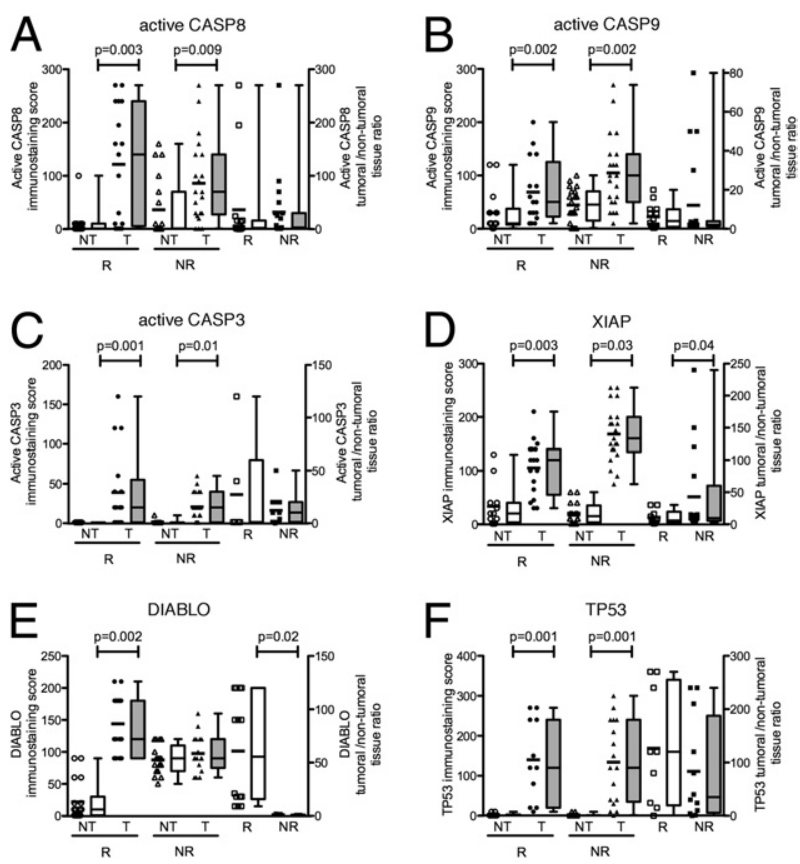

Figure 4. Active CASP8 (A), CASP9 (B), CASP3 (C), XIAP (D), DIABLO (E), and TP53 (F) protein levels in human rectal carcinomas. The immunostaining score was assessed in the tumor (T) and the noncancerous (NT) areas of the tissue sections for each patient in the responsive (R) and nonresponsive (NR) group. Data were expressed as the immunostaining score for NT and T tissue (left) and as the ratio of T/NT expression (right). The results were expressed as scatterplots (black bar, mean) and box-and-whiskers plot, side by side, for each condition.

cerous tissue in both responsive $(P<0.003)$ and nonresponsive $(P<0.03)$ groups. Notably, the ratio for tumor/noncancerous tissue for XIAP was higher in the nonresponsive compared with the responsive group $(P<$ 0.04 , Figure 4D). The expression of DIABLO was significantly elevated in tumors only of the responsive group $(P<0.002$, Figure 4E). The ratio for tumoral/nontumoral tissue was lower in the nonresponsive group for DIABLO $(P<0.02$, Figure 4E). Because the TP53 status correlated to the radiation response of colorectal cancer, ${ }^{27}$ we evaluated its expression. Although TP53 protein levels were significantly higher in tumoral compared with nontumoral tissue in both responsive $(P<0.001)$ and nonresponsive $(P<0.001)$ groups, the ratio of tumoral/nontumoral tissue was similar in both groups (Figure 4F).

Table 1. Radiation Response Variables of XIAP Knockdown and Control SW48 and SW480 Cells

\begin{tabular}{|c|c|c|c|c|c|c|c|}
\hline $\begin{array}{l}\text { Cell line } \\
\text { treatment }\end{array}$ & $\begin{array}{c}\text { Plating } \\
\text { efficiency (\%) }\end{array}$ & $\alpha\left(\mathrm{Gy}^{-1}\right)$ & $\beta\left(G y^{-2}\right)$ & $\mathrm{LD}_{50}$ (Gy) & $\begin{array}{c}\text { Radiation } \\
\text { enhancement ratio }\end{array}$ & $\mathrm{LD}_{10}$ (Gy) & $\begin{array}{c}\text { Radiation } \\
\text { enhancement ratio }\end{array}$ \\
\hline \multicolumn{8}{|l|}{ SW48 } \\
\hline C & $29.81 \pm 2.38$ & 0.1722 & 0.0925 & 1.96 & & 4.14 & \\
\hline $\mathrm{SiO}$ & $29.48 \pm 1.61$ & 0.1959 & 0.0809 & 1.96 & & 4.26 & \\
\hline Six & $34.53 \pm 6.35$ & 0.3601 & 0.0799 & 1.46 & 1.34 & 3.57 & 1.19 \\
\hline \multicolumn{8}{|l|}{ SW480 } \\
\hline C & $29.62 \pm 2.06$ & 0.0260 & 0.0498 & 3.48 & & 6.54 & \\
\hline $\mathrm{SiO}$ & $34.42 \pm 6.46$ & 0.0673 & 0.0405 & 3.39 & & 6.75 & \\
\hline SiX & $35.78 \pm 7.55$ & 0.1966 & 0.0298 & 2.54 & 1.33 & 6.09 & 1.11 \\
\hline
\end{tabular}

Radiation-induced cytotoxicity enhancement factors at $50 \%\left(\mathrm{LD}_{50}\right)$ and $10 \%\left(\mathrm{LD}_{10}\right)$ survival were calculated by transforming the following linear quadratic equation: Surviving Fraction $=\exp \left[(-\alpha \times D)-\left(\beta \times D^{2}\right)\right]$, with $\alpha$ and $\beta$ values of the individual survival curves. $D=$ dose.

$\mathrm{C}$, cells treated only with transfection reagent; SiO, transfection with nonspecific scrambled siRNA; SiX, transfection with XIAP-specific siRNA. 


\section{Discussion}

Preoperative radiotherapy of rectal adenocarcinoma induces a heterogeneous tumor response. Moreover, the rate of complete pathological response induced by chemotherapy, classically given in combination with ionizing radiation, remains wide ( $9 \%$ to $37 \%)$, per a review. ${ }^{28} \mathrm{~A}$ better understanding of the molecular basis of differential radiation responses of rectal adenocarcinoma might open the possibility for identifying a predictive marker to detect responsive and nonresponsive patients. Moreover, the use of a specific molecule, targeted according to the radiosensitivity status, might enhance preoperative radiotherapy efficacy and reduce adverse effects. A high level of apoptotic tumor cells is a predictive marker for tumoral response and long-term local control in colorectal cancer, ${ }^{29}$ and a correlation between radiation-induced apoptosis and radiosensitivity has been identified in vitro. ${ }^{14}$ However, the apoptotic cascade proteins involved in the differential response of patients to radiotherapy have not been elucidated.

In that context, we compared the apoptotic profile after irradiation of known ${ }^{23}$ radiosensitive (SW48) and radioresistant (SW480) cell lines. It is well established that TP53 is involved in regulating radiation-induced apoptosis in colorectal cancer. However, the radiation response of the TP53 mutated cell lines is controversial. ${ }^{30}$ In the case of the colorectal cell lines used in our study, SW48 cells carry the R248W TP53 point mutation, whereas the SW480 cells carry both $\mathrm{R} 273 \mathrm{H}$ and P309S point mutations. $^{31}$ Whether the point mutations (specifically, the $\mathrm{R} 273 \mathrm{H}$ mutation) carried by the SW480 cell line enhance its radiation response status remains an open question. Indeed, R273H mutated cell lines show either higher radioresistance ${ }^{30}$ or no difference in radiosensitivity. ${ }^{32}$ Moreover, Jurkat cells transfected with R273H-mutated TP53 show no difference in their sensitivity compared with control cells. ${ }^{33}$ However, the levels of mutated TP53 protein in SW480 cells are approximately 20-fold higher than in the strain LoVo that expresses wild-type protein. ${ }^{34}$

We observed high levels of pro-apoptotic molecules in the radiosensitive SW48 cells and low levels of proapoptotic molecules in the radioresistant SW480 cells. Moreover, we observed increased protein levels of the anti-apoptotic factor XIAP in SW480 cells. XIAP has a functional role, because inhibition of its expression in the radioresistant (SW480) cells increased their apoptotic rate in both basal (nonirradiated) and irradiated conditions. To associate these preclinical findings at the clinical level, we used a semiquantitative IHC approach to analyze the expression of the caspases in 38 biopsy specimens obtained from 19 responsive and 19 nonresponsive patients with rectal cancer treated with preoperative chemoradiation. Given that the expression of active CASP3, CASP8, and CASP9 was increased in tumor tissue when compared with noncancerous tissue, for both responsive and nonresponsive groups, but without any observed modification in the ratio of tumoral/nontumoral tissue between the two groups, we hypothesized that these molecules might not represent markers for radiation response in rectal carcinoma. However, al- though high levels of active CASP8, CASP9, and CASP3 (pro-apoptotic proteins) were expressed in tumoral tissue compared with noncancerous tissue, the apoptotic index remained low in tumor cells, ${ }^{11,14}$ suggesting a blockade in the cell death process in rectal adenocarcinomas. One putative mechanism underlying this blockade is a deregulation in the expression of XIAP and its inhibitor, DIABLO. We observed an increase for XIAP in the ratio for tumoral/ nontumoral tissue in nonresponsive compared with responsive patients. Conversely, the ratio was dramatically decreased for DIABLO in the nonresponsive patient group. Alternately, increased XIAP levels may down-regulate CASP3 and CASP9 activities, whereas decreased DIABLO levels may permit XIAP [and cellular (c)IAP1 and clAP2] action as anti-apoptotic factors. Thus, the ratio for XIAP and DIABLO might represent a biomarker for radiation responses in rectal cancer. An overexpression of DIABLO in a cervical cancer cell line enhanced the expression and activity of CASP3 and improved the apoptosis-inducing effects of radiation on these cells. ${ }^{35}$ XIAP might have an important role in colorectal cancer development and progression. Indeed, XIAP mRNA was significantly higher in colorectal cancer tumors than in normal mucosa or colorectal adenoma, ${ }^{36}$ and XIAP levels were correlated with the pathological stage of colorectal cancer. ${ }^{36}$ More widely, XIAP might represent a marker for malignancy, because it is highly expressed in most human cancer cells. ${ }^{37-39}$ Notably, Survivin, another member of the IAP family, was also a biomarker in patients with rectal cancer. ${ }^{14}$ Increased Survivin levels were associated with an increased risk of local tumor recurrence and knockdown of Survivin expression in the radioresistant cell line SW480 or in tumor xenografts, resulting in an increased apoptotic fraction or delay in tumor growth after radiation. ${ }^{14}$ The novel finding of our study is the specific differential profile of XIAP and DIABLO expression in the nonresponsive patients. The ratio was obtained by comparing tumoral with noncancerous tissues from the same patients, therefore bypassing individual variation. Moreover, XIAP might be a promising target for molecular tumor therapy. The ability to selectively downregulate XIAP by the siRNA approach has enabled us to highlight the importance of this IAP in resistance to radiotherapy-induced cell death in colorectal carcinoma cells. Indeed, several therapeutic tools in preclinical trials have been developed to inhibit XIAP expression or function, such as antisense oligonucleotides ${ }^{40,41}$ or small molecules that mimic DIABLO action. ${ }^{42}$ These molecules may be new anticancer drugs that mediate down-regulation of XIAP and/or restoration of DIABLO activities in vivo and synergize disease-relevant therapies. Moreover, because high levels of pro-apoptotic molecules (eg, active CASP8) are observed in human rectal carcinoma, sensitization effects of XIAP suppression and/or DIABLO restoration may be augmented by using tumor necrosis factor-related apoptosis-inducing ligand treatment therapeutic tools. ${ }^{43,44}$

In summary, our results suggest the following: XIAP and DIABLO evaluated in tumoral versus nontumoral tissues from rectal biopsy specimens before treatment could serve as a biomarker to identify patients likely to 
either respond or not respond to preoperative radio(chemo)therapy and XIAP might be targeted to increase the therapeutic ratio of radiotherapy for rectal cancer.

\section{Acknowledgment}

We thank Dr. Jean-Louis Requin (The French League against Cancer) for his constant support during this study.

\section{References}

1. Colorectal Cancer Collaborative Group: Adjuvant radiotherapy for rectal cancer: a systematic overview of 8,507 patients from 22 randomised trials. Lancet 2001, 358:1291-1304

2. Rodel C, Martus P, Papadoupolos T, Fuzesi L, Klimpfinger M, Fietkau R, Liersch T, Hohenberger W, Raab R, Sauer R, Wittekind C: Prognostic significance of tumor regression after preoperative chemoradiotherapy for rectal cancer. J Clin Oncol 2005, 23:8688-8696

3. Janjan NA, Abbruzzese J, Pazdur R, Khoo VS, Cleary K, Dubrow R, Ajani J, Rich TA, Goswitz MS, Evetts PA, Allen PK, Lynch PM, Skibber JM: Prognostic implications of response to preoperative infusional chemoradiation in locally advanced rectal cancer. Radiother Oncol 1999, 51:153-160

4. Kapiteijn E, Marijnen CA, Nagtegaal ID, Putter H, Steup WH, Wiggers T, Rutten HJ, Pahlman L, Glimelius B, van Krieken JH, Leer JW, van de Velde CJ: Preoperative radiotherapy combined with total mesorectal excision for resectable rectal cancer. N Engl J Med 2001, 345:638-646

5. Giralt J, Eraso A, Armengol M, Rossello J, Majo J, Ares C, Espin E, Benavente S, de Torres I: Epidermal growth factor receptor is a predictor of tumor response in locally advanced rectal cancer patients treated with preoperative radiotherapy. Int J Radiat Oncol Bio Phys 2002, 54:1460-1465

6. Minsky BD, Cohen AM, Enker WE, Saltz L, Guillem JG, Paty PB, Kelsen DP, Kemeny N, Ilson D, Bass J, Conti J: Preoperative 5-FU, low-dose leucovorin, and radiation therapy for locally advanced and unresectable rectal cancer. Int J Radiat Oncol Biol Phys 1997, 37: 289-295

7. Mohiuddin M, Hayne M, Regine WF, Hanna N, Hagihara PF, McGrath P, Marks GM: Prognostic significance of postchemoradiation stage following preoperative chemotherapy and radiation for advanced/ recurrent rectal cancers. Int J Radiat Oncol Biol Phys 2000, 48:10751080

8. Wong RK, Tandan V, De Silva S, Figueredo A: Pre-operative radiotherapy and curative surgery for the management of localized rectal carcinoma. Cochrane Database Syst Rev 2007, (2):CD002102

9. Watanabe $T$, Komuro $Y$, Kiyomatsu $T$, Kanazawa $T$, Kazama $Y$, Tanaka J, Tanaka T, Yamamoto Y, Shirane M, Muto T, Nagawa H: Prediction of sensitivity of rectal cancer cells in response to preoperative radiotherapy by DNA microarray analysis of gene expression profiles. Cancer Res 2006, 66:3370-3374

10. Suzuki T, Sadahiro S, Fukasawa M, Ishikawa K, Kamijo A, Yasuda S, Makuuchi H, Ohizumi $Y$, Murayama C: Predictive factors of tumor shrinkage and histological regression in patients who received preoperative radiotherapy for rectal cancer. Jpn J Clin Oncol 2004, 34:740-746

11. Rodel C, Grabenbauer GG, Papadopoulos T, Bigalke M, Gunther K, Schick C, Peters A, Sauer R, Rodel F: Apoptosis as a cellular predictor for histopathologic response to neoadjuvant radiochemotherapy in patients with rectal cancer. Int J Radiat Oncol Biol Phys 2002, 52:294-303

12. Ghadimi BM, Grade M, Difilippantonio MJ, Varma S, Simon R, Montagna C, Fuzesi L, Langer C, Becker H, Liersch T, Ried T: Effectiveness of gene expression profiling for response prediction of rectal adenocarcinomas to preoperative chemoradiotherapy. J Clin Oncol 2005, 23:1826-1838

13. Uchida H, Shinoura N, Kitayama J, Watanabe T, Nagawa H, Hamada $\mathrm{H}$ : Caspase-8 gene transduction augments radiation-induced apop- tosis in DLD-1 cells. Biochem Biophys Res Commun 2002, 292:347-354

14. Rodel F, Frey B, Leitmann W, Capalbo G, Weiss C, Rodel C: Survivin antisense oligonucleotides effectively radiosensitize colorectal cancer cells in both tissue culture and murine xenograft models. Int $J$ Radiat Oncol Biol Phys 2008, 71:247-255

15. Nehls O, Okech T, Hsieh CJ, Sarbia M, Borchard F, Gruenagel HH, Gaco V, Porschen R, Gregor M, Klump B: Low BAX protein expression correlates with disease recurrence in preoperatively irradiated rectal carcinoma. Int J Radiat Oncol Biol Phys 2005, 61:85-91

16. Rebischung C, Gerard JP, Gayet J, Thomas G, Hamelin R, LaurentPuig P: Prognostic value of P53 mutations in rectal carcinoma. Int $J$ Cancer 2002, 100:131-135

17. Sohn D, Essmann F, Schulze-Osthoff K, Janicke RU: p21 Blocks irradiation-induced apoptosis downstream of mitochondria by inhibition of cyclin-dependent kinase-mediated caspase-9 activation. Cancer Res 2006, 66:11254-11262

18. Degterev A, Boyce M, Yuan J: A decade of caspases. Oncogene 2003, 22:8543-8567

19. Nunez G, Benedict MA, Hu Y, Inohara N: Caspases: the proteases of the apoptotic pathway. Oncogene 1998, 17:3237-3245

20. Liston P, Fong WG, Korneluk RG: The inhibitors of apoptosis: there is more to life than Bcl2. Oncogene 2003, 22:8568-8580

21. Vaux DL, Silke J: IAPs: RINGs and ubiquitylation. Nat Rev Mol Cell Biol 2005, 6:287-297

22. Du C, Fang M, Li Y, Li L, Wang X: Smac, a mitochondrial protein that promotes cytochrome c-dependent caspase activation by eliminating IAP inhibition. Cell 2000, 102:33-42

23. Dunne AL, Price ME, Mothersill C, McKeown SR, Robson T, Hirst DG: Relationship between clonogenic radiosensitivity, radiation-induced apoptosis and DNA damage/repair in human colon cancer cells. $\mathrm{Br} J$ Cancer 2003, 89:2277-2283

24. Rodel C, Haas J, Groth A, Grabenbauer GG, Sauer R, Rodel F: Spontaneous and radiation-induced apoptosis in colorectal carcinoma cells with different intrinsic radiosensitivities: survivin as a radioresistance factor. Int J Radiat Oncol Biol Phys 2003, 55:13411347

25. Hammami I, Amara S, Benahmed M, El May MV, Mauduit C: Chronic crude garlic-feeding modified adult male rat testicular markers: mechanisms of action. Reprod Biol Endocrinol 2009, 7:65

26. Bozec A, Ruffion A, Decaussin M, Andre J, Devonec M, Benahmed M, Mauduit C: Activation of caspases-3, -6, and -9 during finasteride treatment of benign prostatic hyperplasia. J Clin Endocrinol Metab 2005, 90:17-25

27. Kuremsky JG, Tepper JE, McLeod HL: Biomarkers for response to neoadjuvant chemoradiation for rectal cancer. Int J Radiat Oncol Bio Phys 2009, 74:673-688

28. Huerta S, Gao X, Saha D: Mechanisms of resistance to ionizing radiation in rectal cancer. Expert Rev Mol Diagn 2009, 9:469-480

29. Scott N, Hale A, Deakin M, Hand P, Adab FA, Hall C, Williams GT, Elder JB: A histopathological assessment of the response of rectal adenocarcinoma to combination chemo-radiotherapy: relationship to apoptotic activity, p53 and bcl-2 expression. Eur J Surg Oncol 1998 24:169-173

30. Ng CE, Banerjee SK, Pavliv M, Wang G, Raaphorst GP, Aubin RA p53 Status, cellular recovery and cell cycle arrest as prognosticators of in vitro radiosensitivity in human pancreatic adenocarcinoma cell lines. Int J Radiat Biol 1999, 75:1365-1376

31. Kastrinakis WV, Ramchurren N, Rieger KM, Hess DT, Loda M, Steele G, Summerhayes IC: Increased incidence of p53 mutations is associated with hepatic metastasis in colorectal neoplastic progression, Oncogene 1995, 11:647-652

32. Kataoka Y, Murley JS, Patel R, Grdina DJ: Cytoprotection by WR-1065, the active form of amifostine, is independent of p53 status in human malignant glioma cell lines. Int J Radiat Biol 2000 76:633-639

33. Iwamoto KS, Mizuno T, Ito T, Tsuyama N, Kyoizumi S, Seyama T: Gain-of-function p53 mutations enhance alteration of the T-cell receptor following X-irradiation, independently of the cell cycle and cell survival. Cancer Res 1996, 56:3862-3865

34. Rochette PJ, Bastien N, Lavoie J, Guerin SL, Drouin R: SW480, a p53 double-mutant cell line retains proficiency for some p53 functions. $J$ Mol Biol 2005, 352:44-57 
35. Zheng LD, Xiong ZF, Zhu JW, Wang ZH: Effects of Smac gene over-expression on the radiotherapeutic sensitivities of cervical cancer cell line HeLa. Chin Med J (Engl) 2005, 118:226-230

36. Takeuchi H, Kim J, Fujimoto A, Umetani N, Mori T, Bilchik A, Turner R, Tran A, Kuo C, Hoon DS: X-linked inhibitor of apoptosis protein expression level in colorectal cancer is regulated by hepatocyte growth factor/C-met pathway via Akt signaling. Clin Cancer Res 2005, 11:7621-7628

37. Holcik M, Korneluk RG: XIAP, the guardian angel. Nat Rev Mol Cell Biol 2001, 2:550-556

38. Sasaki H, Sheng Y, Kotsuji F, Tsang BK: Down-regulation of X-linked inhibitor of apoptosis protein induces apoptosis in chemoresistant human ovarian cancer cells. Cancer Res 2000, 60:5659-5666

39. Li J, Sasaki H, Sheng YL, Schneiderman D, Xiao CW, Kotsuji F, Tsang BK: Apoptosis and chemoresistance in human ovarian cancer: is Xiap a determinant? Biol Signals Recept 2000, 9:122-130

40. Amantana A, London CA, Iversen PL, Devi GR: X-linked inhibitor of apoptosis protein inhibition induces apoptosis and enhances chemo- therapy sensitivity in human prostate cancer cells. Mol Cancer Ther 2004, 3:699-707

41. Devi GR: XIAP as target for therapeutic apoptosis in prostate cancer. Drug News Perspect 2004, 17:127-134

42. Berger R, Jennewein C, Marschall V, Karl S, Cristofanon S, Wagner L, Vellanki SH, Hehlgans S, Rodel F, Debatin KM, Ludolph AC, Fulda S: NF-kappaB is required for Smac mimetic-mediated sensitization of glioblastoma cells for gamma-irradiation-induced apoptosis. Mol Cancer Ther 2011, 10:1867-1875

43. Cummings J, Ward TH, LaCasse E, Lefebvre C, St-Jean M, Durkin J, Ranson M, Dive C: Validation of pharmacodynamic assays to evaluate the clinical efficacy of an antisense compound (AEG 35156) targeted to the $\mathrm{X}$-linked inhibitor of apoptosis protein XIAP. $\mathrm{Br} J$ Cancer 2005, 92:532-538

44. Schimmer AD, Dalili S, Batey RA, Riedl SJ: Targeting XIAP for the treatment of malignancy. Cell Death Differ 2006, 13:179-188 